Viso - Cadernos de estética aplicada Revista eletrônica de estética

ISSN 1981-4062

No 24, jan-jun/2019

http://www.revistaviso.com.br/
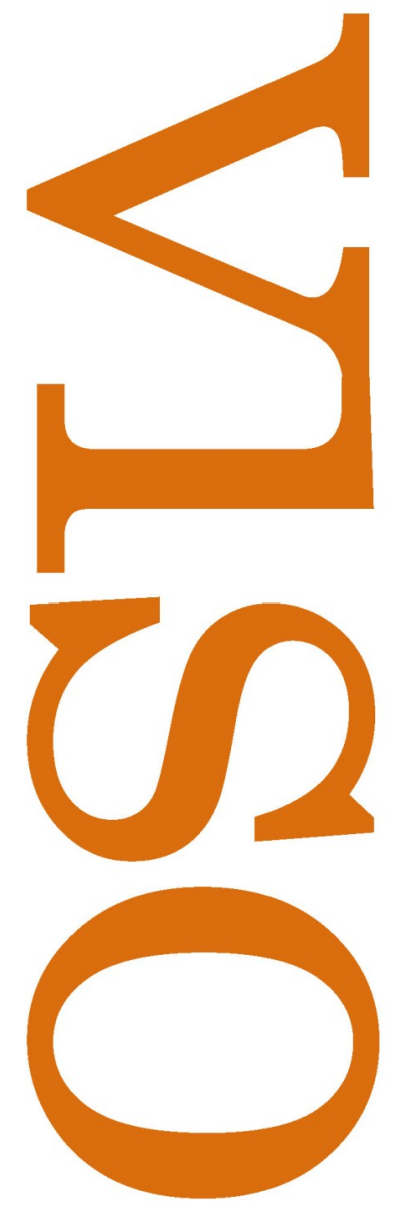

\title{
Medea Mina Jeje e o sacrifício do filho morto Alexandre Costa
}




\section{RESUMO}

Medea Mina Jeje e o sacrifício do filho morto

O artigo faz uma análise de Medea Mina Jeje, peça de teatro recentemente apresentada em São Paulo concebida pelo ator Kenan Bernardes, com dramaturgia de Rudinei Borges e direção de Juliana Monteiro.

Palavras-chave: Medeia - tragédia - crítica da cultura

\section{ABSTRACT}

Medea Mina Jeje and the Sacrifice of the Dead Son

This paper analyzes the play Medea Mina Jeje, conceived by actor Kenan Bernardes, written by Rudinei Borges and directed by Juliana Monteiro, which has been recently staged in Sao Paulo.

Keywords: Medea - Tragedy - Critique of culture 
COSTA, A. "Medea Mina Jeje e o sacrifício do filho morto". In: Viso: Cadernos de estética aplicada, v. XII, n. 24 (jan-jun/2019), pp. 1-11.

DOI: $10.22409 / 1981-4062 / v 24 i / 309$

Aprovado: 17.02.2019. Publicado: 30.06.2019.

(C) 2019 Alexandre Costa. Esse documento é distribuído nos termos da licença Creative Commons Atribuição-NãoComercial 4.0 Internacional (CC-BY-NC), que permite, exceto para fins comerciais, copiar e redistribuir o material em qualquer formato ou meio, bem como remixá-lo, transformá-lo ou criar a partir dele, desde que seja dado o devido crédito e indicada a licença sob a qual ele foi originalmente publicado.

Licença: http://creativecommons.org/licenses/by-nc/4.0/deed.pt_BR

Accepted: 17.02.2019. Published: 30.06.2019.

(C) 2019 Alexandre Costa. This document is distributed under the terms of a Creative Commons Attribution-NonCommercial 4.0 International license (CC-BY-NC) which allows, except for commercial purposes, to copy and redistribute the material in any medium or format and to remix, transform, and build upon the material, provided the original work is properly cited and states its license.

License: http://creativecommons.org/licenses/by-nc/4.0/ 
É com clareza e precisão que a sinopse de Medea Mina Jeje apresenta o seu enredo: "Ao saber que seu filho Age seria perseguido, mutilado e novamente aprisionado à boca de uma mina de ouro, Medea, uma mulher negra e escravizada, decide por sacrificá-lo, numa tentativa de libertá-lo da própria sina". ${ }^{2}$ Esta história, a história a ser contada pela voz e pelos cantos da própria Medea, aqui enfim protagonista, é o começo de um grande acerto. Trata-se de um enredo que executa um duplo movimento: tanto oferece, sobre a Medeia de Eurípides, uma instigante visita ao seu ponto mais decisivo e difícil, o célebre infanticídio cometido por Medeia ao matar os seus dois filhos - e cujas recepção e interpretação se fizeram historicamente controversas - como nos oferece, sobre o nosso tempo e o nosso país, a dolorosa evocação de imagens e memórias de um passado que a sociedade brasileira tradicionalmente empenhou-se em esquecer; um passado que, na contramão desse esquecimento, continua a atuar e refletir-se decididamente na realidade social, cultural e econômica do país. A fim de contar uma das inúmeras possíveis histórias recalcadas por essa seletiva memória nacional, arrancando-a do seu silente esquecimento, o enredo da peça opera um deslocamento necessário da história de Medeia para esta Medea jeje, a um só tempo brasileira e não-brasileira, estranha e familiar, e que partilha com a Medeia grega a decisão e o ato infanticidas. Tal como na peça de origem, sobretudo se desenraízada do seu complexo contexto, a trama arremessa o público diretamente à pergunta inevitável: o que levaria uma mãe a matar o próprio filho? Que contexto justificaria um ato tão extremo?

Diga-se de antemão que Medea Mina Jeje não pretende ser, em momento algum, uma adaptação da peça original, antes herda-lhe de forma pontual e estratégica o ato mais emblemático e célebre da obra de Eurípides, enriquecendo-se de sua carga e potência simbólicas; ato polêmico e controverso, que torna difícil a sua recepção e interpretação desde a sua primeira apresentação em 431 a.C.: que Eurípides nos apresente uma heroína que mata os próprios filhos, sendo, em seguida, elevada à apothéosis, imagem última de uma Medeia erguida aos céus por meio da carruagem do Sol, divindade ancestral de quem ela era neta. ${ }^{3}$ Operando uma conexão direta deste ato com um outro, o de uma mulher africana, transferida do antigo reino de Dahomé para a realidade escravocrata do Brasil colonial do século XVIII, a peça expõe o ambiente insalubre e terrivelmente violento que leva Medea a decidir-se pelo sacrifício de seu filho Age, nascido em plena travessia para terras brasileiras. Trabalhando nas minas de Minas Gerais, Medea perde seu filho para o senhor dos escravos; perde seu filho para a busca 
do ouro nas minas de Vila Rica de Nossa Senhora do Pilar de Ouro Preto, sendo ele um dos inúmeros filhos e ela uma das inúmeras mães submetidos à exploração do trabalho que moveu a morticida economia escravagista do Brasil Colônia.

Com dramaturgia de Rudinei Borges, direção de Juliana Monteiro e atuação de Kenan Bernardes, Medea Mina Jeje une nesse gesto pontual tempos distintos e também distantes, aproximando Medeia e Medea em torno a esse ato principal que thes é comum, sem deixar de lado - eis o mais relevante - as circunstâncias e o contexto que despontam como sua motivação. Outros elementos constróem sutilmente o paralelo e a proximidade entre as personagens, tais como o desterro e a franca decepção ante o novo mundo que as "recebe" e que faz delas, mais do que estrangeiras, figuras estranhas, indesejadas. E tal como a Medeia grega, esta Medea jeje também evoca seus deuses e pratica seus sortilégios, ameaçados de extinção pela tinta do esquecimento e pela asfixia embutida no apagar dos idiomas; ambas bradam os seus nomes, entoam os seus cantos, conjuram suas divindades ancestrais, ministram os seus encantamentos. Este traço comum, de feição mítica e religiosa, que inscreve as personagens no universo do rito e thes confere um aura quase litúrgica, é de extrema importância para que se reconheça a complexidade e o teor real que circunda o temível e extremo ato que praticam: em suas perspectivas e sensibilidades, o que suas mãos e intenções realizam não é um assassinato, mas propriamente um sacrifício ${ }^{4}$ - um conjunto de atos e procedimentos que visam a infundir caráter sagrado em uma determinada ação.

O rito, em sua cuidada, meticulosa forma de proceder, é também consciência do rito: estas duas Medeias, a grega e a jeje, sabem exatamente o que fazem, e com lucidez estranha a nós ministram um ato extremo, diante do qual não raro nos arrogamos poder julgá-las e demonizá-las deste ou daquele modo. Atitude que negligencia que nada há que seja puramente em si, deixando de reconhecer o contexto, a motivação e a sabedoria - o texto de Eurípides insiste em dizer da sophía de Medeia - que a um só tempo circundam e preenchem por dentro cada um dos seus atos, cada um dos seus passos. Sem o reconhecimento de que o ato de matar o(s) próprio(s) filho(s) ocorre como sacrifício - independentemente de o quanto isso afronte mais ou menos esta ou aquela moral que seja ou não a de cada um de nós, espectadores deste ou daquele tempo histórico -, perdemos completamente a chance de adentrar pela delicada e terrível complexidade de que este ato se reveste; perdemos a possibilidade de sermos tocados mais fundamente pela provocação a que essas obras dramáticas nos querem expor. Afastamo-nos, inclusive e sobretudo, do binômio que instaura a tensão primordial do enredo e do perfil de ambas as personagens, a conjugação entre suplício materno e a decisão pelo sacrifício de um filho, uma decisão trágica, porque não garante a superação desse suplício, antes o mantém e mesmo ameaça ampliá-lo. A realização do sacrifício, sua condução ritualística, é o sinal e a indicação de que essas mães levam seus filhos à morte em nome de algo que julgam ser um bem maior; ou, correlatamente, em nome de Ihes evitar um mal ainda maior, de modo que, por este ou aquele ângulo, jamais deixa de estar em jogo o bem do próprio filho sacrificado, o que por fim é o que torna o sacrifício 
um ato que thes seja possível, realizável, e que surge intrinsecamente à dilacerante experiência desse suplício. Esse ato extremo encontra no amor pelo filho a ser morto um dos seus condicionantes. Trata-se de um ato de terrível complexidade, em que concorrem as mais diversas e mesmo heterogêneas motivações, mas sem a percepção de sua feição também amorosa - feição particularmente sublinhada e bem manejada por Medea Mina Jeje para a sua protagonista - desfigura-se a radicalíssima dificuldade vivida pelas personagens, o que favorece a tradicional tendência a dissolver essa mesma dificuldade no ácido das simplificações morais.

A dimensão sacrificial dessas mortes encarna-se cenicamente na atmosfera de rito que as personagens imprimem na elaboração e execução de seus intentos. A produção dessa atmosfera, por sua vez, é justamente uma exigência dessa feição amorosa que, ao menos no caso desta Medea jeje, opera como a grande força motora do seu gesto; o rito traduz o amor e o cuidado da mãe pelo filho, bem como mitiga a própria dor materna, sentimento excruciante que convive com a necessidade de efetivar o sacrifício. É preciso dizer que a dramaturgia e a direção do espetáculo esmeram-se em delinear com firmeza este lugar como sendo o êthos dessa Medea afrobrasileira. Se a Medeia grega parece inscrita numa ambiguidade que acirra a dúvida e a dificuldade em identificar as suas reais motivações, elemento que, somado ao preconceito histórico de que a personagem padece, fez da Medeia de Eurípides muitas vezes a evocação da memória de um monstro abominável ${ }^{5}$, nem o texto de Rudinei Borges, nem a direção de Juliana Monteiro permitem similar destino à sua heroína, conduzindo com êxito o propósito de inseri-la milimetricamente dentro desse espaço ético de ação.

Dentres outros, talvez o feito maior da peça seja justamente este, a sensibilidade com que deixa aflorar a aura do rito; tomada como um todo, Medea Mina Jeje pode ser vista como uma performance cênica que realiza a forma do rito em feitio de oração ${ }^{6}$ : descrita pelas palavras da própria mãe, o modo como ela, Medea, narra a sua história faz com que 0 ar que se respira ao longo da breve e contundente encenação ${ }^{7}$ jamais deixe de exalar e criar essa atmosfera sacralizante, como se fosse uma prece, por vezes também um lamento, com que se embalam a dor de Medea e a morte de seu filho. Como quem envolve a própria narrativa numa mortalha, a morte de Age por sua mãe jamais corre o risco de ser sentida pelo público fora dessa singela e pungente moldura.

Para o conseguimento desse efeito e criação dessa aura contribui em muito uma série de decisões dramáticas, a começar pelo enredo, como já referido, delicadamente pinçado de uma cruenta página da nossa história: Medea Mina Jeje desvela o horror geral da escravidão no Brasil evocando uma memória particularmente sórdida e empiricamente verdadeira de suas práticas, "o trabalho penoso e aterrador nas minas de ouro que moveram a economia do Brasil durante sÉculos, mesmo a desmantelar vidas inteiras num genocídio silencioso que marca, com ferro e fogo, a história do país a partir do signo da violência". ${ }^{8}$ 
Nessas minas - a Mina Jeje, de onde a montagem recolhe a sua história, era apenas uma dentre tantas -, hoje locais de visitação turística, esse "trabalho aterrador" chegara aos píncaros de sua crueldade, ao recorrer à castração, face à indescritível finalidade de que os meninos que nelas trabalhavam escavando ouro não crescessem para além do tamanho estreito dos seus túneis e dos espaços exíguos de sua precária "arquitetura". O menino de Medea, Age, estava destinado a essa sina. Seu sacrifício liberta-o dela:

\author{
Jazão me diz que maior castigo \\ A ser oferecido ao menino \\ É viver vida toda \\ Dentro da mina \\ Feito um bicho que cava terra \\ Sem que tenha filhos. \\ Dizem em cochichos: \\ Menino cresce mais alto que teto da mina \\ É preciso embriagar menino \\ Que cresce mais alto que teto da mina \\ É preciso castrar menino.
}

Porque o filho desta Medea já nasce morto, destinado a destino conhecido, obrigado a uma vida exangue e mortificante, ela decide matá-lo. Tal como Aquiles diante de Tétis ${ }^{10}$, sua mãe, Medea só pode escolher entre a morte e a morte:

Mata hoje teu filho.

Que não matem amanhã teu filho

Dentro da mina.

ida toda dentro da mina.

Entre a morte que é morte e a vida que é mortiça, que é morte em vida, Medea escolhe a morte que livra da mortificação, a morte que portanto ainda contém algum quinhão de liberdade; a morte que livra Age do morticínio contínuo de uma "vida toda dentro da mina", castrado, expropriado de si até o seu descarte final - até atingir o limite de mercadoria inútil e o paradoxo de uma força de produção improdutiva. Diante da magnitude dessa vileza, frente a este indizível contexto, é imperioso recolocar a pergunta: o que significa matá-lo? Ele, bem como outros meninos e meninas, e também a própria Medea, pertencem a Jasão; pertencem ainda mais radicalmente àqueles a quem Jasão-capitão-do-mato pertence; àqueles que sequer aparecem em cena, o rosto e as mãos invisíveis do senhor, tenha ele o título de Barão ou de "livre mercado". Num caso e no outro, fazem dessas vidas comércio, sem pudor de tratar e destratar suas mercadorias, sua propriedade, como bem Ihes aprouver. É diante dessa desumanização e em gritante contraste com ela que o ato desta Medea jeje recupera, desde a sua origem na peça de Eurípides, o seu "oculto" sentido: insubordinar-se diante de forças supostamente imbatíveis; resistir, mesmo que a tamanho preço, a estar à deriva e em função de uma vontade que dela se assenhoreia. O sacrifício do filho, além de livrá-lo de uma morte em vida, representa também a resistência possível, como quem, sabendo do 
inelutável dessa luta, resiste até a última trincheira, até a derradeira fibra do próprio corpo, como se por meio de seu ato, gritasse: "não serão eles donos da nossa vida; muito menos serão da nossa morte".

A mina em que Age cresce apenas até não poder mais crescer, apenas até o momento de ser aprisionado para a o "corretivo" da castração, é muito bem explorada como signo de opressão pelo cenário que, ao reproduzi-la, evoca a força de coerção embutida na própria forma-mina: espaço estreito e árido, sufocante e malsão. Matizes de luz e som multiplicam esse espaço mímino, de inteligente economia cênica e cenográfica, reiterando novamente a habilidade do trabalho desenvolvido por Juliana Monteiro. ${ }^{11}$ Logo de início, o que o espectador testemunha, visualmente, é o deserto da mina, cenário para os olhos, ao mesmo tempo em que ouve o mar, "paisagem" para os ouvidos; o mar cujo rumor das ondas remete não somente à travessia que apartara Medea de sua terra, mas também à enorme discrepância que contrasta, nesse jogo de luz e som, olhos e ouvidos, a realidade cruamente material e opressora do deserto, da mina, e o campo infinito do desejo e do sonho, que aquela realidade opressora, literalmente, castra.

A inabarcável dimensão do oceano, que nos chega por meio dessas contrastantes emissões sonoras, representa ainda o espaço de uma esperança possível. O deserto, o sertão, virando mar. $O$ texto da peça, assinado por Rudinei Borges, perfaz esse movimento, começando e terminando com os mesmos versos, nos quais Medea conclama o filho a avistar um fiapo de luz. Um fiapo de luz em meio à escuridão da mina; um fiapo de luz que se esgueire por uma brecha qualquer, deixando entrever algum raio de sol que ilumine o seu (im)possível futuro: "Avista fiapo de luz, Age. É lá fora, menino". Talvez a força principal do texto, de acentuado teor poético, seja o de empenhar-se em ampliar o fiapo de luz que Medea guarda para Age, estendendo-o também para ela e para os seus filhos; e para os filhos dos seus filhos. Por isso vemos surgir diante de nós uma Medea incomodamente tão atual, incomodamente tão familiar a tantos dos seus descendentes que nela se reconhecem; que se reconhecem num espelho que reflete um retrato infelizmente fiel da injustiça e desigualdade sociais que tão fundamente marcam a sociedade brasileira:

\footnotetext{
Medea carrega cântaro de água na cabeça.

Medea carrega água dia todo.

Medea vai parir outros meninos

comoutras pretas vão parir outros meninos.

Até que se tenham muitos meninos a cavar mina

Até que dono da mina tenha muito ouro.
}

As citações ao texto original da peça, composto em forma de poema, talvez sejam suficientes para que se percebam alguns aspectos da sua escrita que favorecem a dinâmica do espetáculo e a construção da aura de sua protagonista. Trata-se de um poema curto, conciso, de pronúncia contida, em que irrompem imagens ásperas e impactantes, tanto dando vazão à fala "seca" que a situação exige, quanto exercitando 
alguma aproximação com o que fosse uma língua de época, em que se confundem a origem na terra perdida e o português do mineiro e do minério, fala do senhor que escraviza. Por meio desses recursos, a elaboração poética do texto concede a Medea uma fala própria, muito singular em seu desenho e seu sotaque. Uma fala um tanto estranha, um tanto estrangeira e também estremecida, mas ainda assim firme, grave, enxuta. São tempos árduos, vidas duras, as de Medea e de Age, e o "luxo" do excesso seria odiosa gordura à fala: tanto a ação como a voz desta Medea guiam-se pela medida da necessidade e da urgência e se deixam marcar com o selo ritual do sacrifício.

Estas características da escrita poética da dramaturgia encontram em Kenan Bernardes um ator não só capaz de traduzi-las em seu corpo e sua voz, como também de valorizálas. Responsável pela concepção e produção geral da montagem, a performance cênica de Kenan conjuga com maestria canto, dança, fala e também silêncio, desdobrando-se em narrador, ator e bailarino do espetáculo, com o que, sozinho em palco, imprime grande movimento e expressividade à sua Medea.

Por fim, não seria possível deixar de considerar a sugestiva carga simbólica que gravita em torno a um dos signos centrais da peça: não aquele que coincide com o seu ato final e extremo, mas aquele que mais diretamente simboliza a sua motivação; aquele signo que revela o limite, para Medea, daquilo que não é mais possível suportar - a castração. O recurso à castração, em nome da finalidade já mencionada, revela-se um ato que é, ele mesmo, uma metáfora pronta. Uma metáfora perfeita, inteira, para a imagem de um passado e de um presente que o país historicamente jamais assumiu para si. Metáfora que se torna tão mais terrível ao se saber que não é metáfora: a castração como prática de mutilação que atendia aos interesses de produção de força de trabalho escravo e ao seu mais vantajoso proveito é um dado real de nossa história, que com derradeiro grau de ironia e desconforto vale também como imagem simbólica do pulso opressor da cultura brasileira, que procura apequenar e castrar um sem número de suas gentes, inibindo violentamente as suas possibilidades de vida e crescimento.

Medea Mina Jeje oferece a seu público a lembrança e a experiência que mostram que a tradição dos oprimidos é também uma tradição e que essa tradição possui o seu saber e a sua memória; lembrança e experiência que mostram, igualmente, que "a tradição dos oprimidos nos ensina que o estado de exceção no qual vivemos é a regra" ${ }^{12}$, assim como a história de Medea e a sua decisão pelo sacrifício do filho revelam mais do que uma gente que morre sem querer morrer. Se os versos de Zé Ketti que servem de epígrafe a este texto acusam o descaso que faz com que mortes plenamentes evitáveis tornem-se costumeiras, fazendo do luto uma rotina - "Acender as velas/ já é profissão/ quando não tem samba,/ tem desilusão" -, expressando essa condição ao cantar "e a gente morre sem querer morrer", o enredo de Medea Mina Jeje apresenta um caso de circunstância tão extrema desse normativo "estado de exceção" que a voz de sua protagonista se ergue para mostrar que há, também, gente que mata sem querer matar. A peça anuncia, para esta Medea e também para aquela, a de Eurípides, que o ato de matar os próprios 
filhos realiza a conversão de suas mortes em sacrifício, cumprindo a sacralização de um filho (já) morto. O mais profundo sortilégio dessas "bruxas" é o segredo e a coragem de transmutar uma morte em outra. Medea Mina Jeje é um espetáculo que deve ser visto.

\section{Medea Mina Jeje, ficha técnica:}

Concepção, atuação e produção geral: KENAN BERNARDES

Dramaturgia e pesquisa teórica: RUDINEI BORGES

Direção, espaço cênico e direção de movimento: JULIANA MONTEIRO

Luz: WAGNER ANTÔNIO

Assistente de iluminação: DOUGLAS DE AMORIM

Desenho de som e difusão sonora: JOãO PAULO NASCIMENTO

Figurino e visagismo: CAROL BADRA

Desenho de canto e provocação em ação vocal: MARIA CORDÉLIA

Provocação corporal: LUCIANA LYRA

Orientação na pesquisa teórica: SALLOMA SALLOMÃO

Artista gráfico: MURILO THAVEIRA

\footnotetext{
* Alexandre Costa é professor do Departamento de Filosofia da UFF.

${ }^{1}$ Versos de Acender as velas, samba de Zé Ketti gravado pela primeira vez em 1965.

${ }^{2}$ Colhida do material de divulgação e projeto final da peça, gentilmente cedidos pelos seus autores.

${ }^{3}$ Da má recepção do público diante do desfecho da peça talvez seja suficiente lembrar que _ fazia parte da tetralogia que obteve o terceiro e último lugar nas Grandes Dionisíacas daquele ano.

${ }^{4}$ Esta palavra, de origem latina, significa literalmente "ofício sagrado".

${ }^{5}$ Recorde-se, a título de exemplo, a Medea de Sêneca, tragédia que mostra bem como a recepção latina da peça original de Eurípides enveredou por essa direção, abrindo ou fortalecendo, a partir de aí, uma herança dramática que passa a irradiar, em torno à figura de Medeia, a imagem de uma mulher torpe, desequilibrada e cruel ao limite da aberração.
}

${ }^{6}$ Menção ao célebre samba de Noel Rosa e Vadico, de 1933.

${ }^{7}$ A duração do espetáculo é de 40 minutos aproximadamente.

${ }^{8}$ Citado a partir do texto de apresentação da peça, por Rudinei Borges.

${ }^{9}$ Versos extraídos do poema que constitui o texto da peça.

${ }^{10}$ llíada, IX, vv. 410-416.

${ }^{11}$ No que se refere às operações de luz e de som, devem ser mencionados, respectivamente, os trabalhos de Wagner Antônio e João Paulo Nascimento. Ao fim deste texto, apresentamos a ficha técnica do espetáculo. 
${ }^{12}$ Citação à Tese VIII de Sobre o conceito de história, de Walter Benjamin. In: LÖWY, M. Walter Benjamin: aviso de incêndioTradução das Teses por Jeanne Marie Gagnebin e Marcos Müller. São Paulo: Boitempo Editorial, 2005, p. 83. 